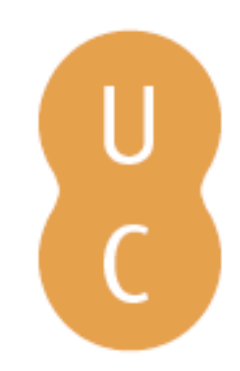

\title{
pompalina
}

\section{Processssos ecológicos e serviços} $\begin{array}{ll}\text { Autor(es): } & \text { Ferreira, Verónica; Canhoto, Cristina; Pascoal, Cláudia; Graça, Manuel } \\ & \text { A.S. }\end{array}$

Publicado por: Imprensa da Universidade de Coimbra

URL

persistente: URI:http://hdl.handle.net/10316.2/45888

DOI: DOI:https://doi.org/10.14195/978-989-26-1624-7_12

Accessed : $\quad$ 26-Apr-2023 15:04:55

A navegação consulta e descarregamento dos títulos inseridos nas Bibliotecas Digitais UC Digitalis, UC Pombalina e UC Impactum, pressupõem a aceitação plena e sem reservas dos Termos e Condições de Uso destas Bibliotecas Digitais, disponíveis em https://digitalis.uc.pt/pt-pt/termos.

Conforme exposto nos referidos Termos e Condições de Uso, o descarregamento de títulos de acesso restrito requer uma licença válida de autorização devendo o utilizador aceder ao(s) documento(s) a partir de um endereço de IP da instituição detentora da supramencionada licença.

Ao utilizador é apenas permitido o descarregamento para uso pessoal, pelo que o emprego do(s) título(s) descarregado(s) para outro fim, designadamente comercial, carece de autorização do respetivo autor ou editor da obra.

Na medida em que todas as obras da UC Digitalis se encontram protegidas pelo Código do Direito de Autor e Direitos Conexos e demais legislação aplicável, toda a cópia, parcial ou total, deste documento, nos casos em que é legalmente admitida, deverá conter ou fazer-se acompanhar por este aviso.

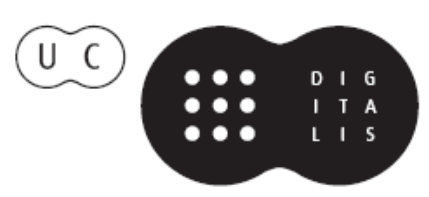


MARIA JOÃO FEIO

VERÓNICA FERREIRA

(EDS.)

\section{IMPRENSA DA \\ UNIVERSIDADE \\ DE COIMBRA \\ COIMBRA \\ UNIVERSITY \\ PRESS}

\section{RIOS DE PORTUGAL COMUNIDADES, PROCESSOS E ALTERAÇÕES}




\section{CA P ÍT ULO 12 \\ PROCESSOS ECOLÓGICOS E SERIÇOS}

Verónica Ferreira ${ }^{1}$, Cristina Canhoto ${ }^{2}$, Cláudia Pascoal $^{3}$ \& Manuel A.S. Graça ${ }^{4}$

${ }^{1}$ MARE - Centro de Ciências do Mar e do Ambiente, Departamento de Ciências da Vida, Faculdade de Ciência e Tecnologia, Universidade de Coimbra, Portugal, veronica@ci.uc.pt ${ }^{2} \mathrm{CEF}$ - Centro de Ecologia Funcional, Departamento de Ciências da Vida, Faculdade de Ciência e Tecnologia, Universidade de Coimbra, Portugal, ccanhoto@ci.uc.pt ${ }^{3}$ CBMA - Centro de Biologia Molecular e Ambiental, Departamento de Biologia, Universidade do Minho, Portugal e IB-S - Instituto de Ciência e Inovação para a Bio-sustentabilidade, Universidade do Minho, Portugal, cpascoal@bio.uminho.pt ${ }^{4}$ MARE - Centro de Ciências do Mar e do Ambiente, Departamento de Ciências da Vida, Faculdade de Ciência e Tecnologia, Universidade de Coimbra, Portugal, mgraca@ci.uc.pt

Resumo: Os pequenos ribeiros de floresta constituem parte integrante da paisagem, estando representados em elevado número e ocupando uma posição de cabeceira nas bacias hidrográficas. Nestes ribeiros decorrem processos que podem afetar o balanço energético e o ciclo dos nutrientes a grandes escalas. Estes ribeiros, sendo ensombrados, obtêm da matéria orgânica (maioritariamente folhas produzidas pela floresta ripária) grande parte da energia e nutrientes que circulam pela cadeia trófica aquática. A decomposição destas folhas compreende várias fases, em que estão envolvidos diferentes tipos de organismos, e é sensível a variações ambientais. Em ribeiros menos ensombrados, a produção primária é um 
processo basal. A energia e nutrientes colocados à disposição pela decomposição das folhas ou pela produção primária são incorporados nos níveis tróficos mais elevados da teia alimentar. Estes processos asseguram a prestação de serviços às populações (p.ex., água de boa qualidade para consumo). Estes serviços ficarão em risco caso haja perturbações nos processos que estão na sua origem devido a atividades antropogénicas.

Palavras-chave: decomposição de folhas, decompositores microbianos, invertebrados fragmentadores, produção primária, produção secundária

\section{Pequenos ribeiros de floresta}

Os pequenos ribeiros de floresta constituem a maioria dos cursos de água das bacias hidrográficas em regiões temperadas. Estes ribeiros encontram-se essencialmente nas zonas de cabeceira, onde a floresta nativa e a silvicultura prevalecem; nas zonas médias e baixas das bacias hidrográficas há uma maior área de agricultura e de zonas urbanas.

Os pequenos ribeiros são estreitos (alguns centímetros a poucos metros) e são geralmente ensombrados pela vegetação ripária. Além de sombra, a vegetação ripária produz grande quantidade de detritos vegetais (Figura 12.1). A produção anual de detritos nas florestas dominadas por espécies caducifólias na Serra do Açor e nas plantações de eucalipto na Serra do Caramulo foi estimada em 261 e $204 \mathrm{~g} / \mathrm{m}^{2}$, respetivamente ${ }^{1}$. Na Mata da Margaraça (Serra do Açor), área de floresta nativa mista dominada por castanheiros, há registo da produção anual de $715 \mathrm{~g}$ de detritos vegetais $/ \mathrm{m}^{2}{ }^{2}$.

Em florestas dominadas por espécies caducifólias, a entrada de detritos vegetais nos ribeiros ocorre essencialmente durante o outono 
e o inverno (mais de $70 \%$ da entrada anual) ${ }^{1,2}$. Em plantações de eucalipto, a entrada de detritos nos ribeiros ocorre principalmente no verão e representa cerca de $45 \%$ da entrada anual ${ }^{1}$. Em qualquer dos casos, os detritos são essencialmente compostos por folhas (mais de 60\%), com menor proporção de material lenhoso (ramos e troncos) e de estruturas reprodutivas (flores e frutos) ${ }^{1,2}$.

Os detritos entram nos ribeiros diretamente, logo após a queda (entrada por via vertical), ou caem no solo da floresta onde começam a ser decompostos pelos organismos terrestres podendo ser mais tarde arrastados para os ribeiros (entrada por via lateral). A entrada lateral de folhas garante o suplemento de alimento para os organismos aquáticos depois do pico de produção de folhas no outono. As folhas acumulam-se no leito dos ribeiros até serem consumidas pelos organismos aquáticos ou serem arrastadas pela corrente para outros locais mais a jusante ${ }^{1-4}$. A retenção de folhas no leito depende das suas características e das características dos ribeiros ${ }^{5}$. Folhas mais flexíveis (p.ex., folhas de amieiro, Alnus glutinosa ou de castanheiro, Castanea sativa) são mais facilmente retidas entre as pedras e pequenos ramos do que folhas mais rígidas (p.ex., folhas de carvalho, Quercus robur ou de eucalipto, Eucalyptus globulus) (Figura 12.1). Ribeiros com maior número de estruturas proeminentes (p.ex., pedras e troncos) e menor caudal retêm as folhas mais facilmente. A maior parte das folhas é retida a poucos metros do local de entrada na água; por exemplo, 50\% das folhas são retidas a menos de $20 \mathrm{~m}$ do local de entrada na água e mais de $90 \%$ das folhas são retidas a menos de 40 a $90 \mathrm{~m}$ do local de entrada em ribeiros na Serra da Lousã e na Serra do Caramulo5

A quantidade de folhas acumuladas no leito dos ribeiros de floresta resulta então do balanço entre a quantidade de folhas que entra na água (por via vertical e lateral e transportada de setores a montante), a quantidade de folhas que é retida no local ou transportada para jusante e a taxa a que as folhas são decompostas ${ }^{1-3}$. 
Por exemplo, em ribeiros de floresta caducifólia da Serra do Açor foi registada uma acumulação média anual de $669 \mathrm{~g}$ de detritos/ $\mathrm{m}^{2}{ }^{1}$; o valor foi de $6,3 \mathrm{~g} / \mathrm{m}^{2}$ para a Ribeira de São João (Serra da Lousã $)^{6}$ e de $1880 \mathrm{~g} / \mathrm{m}^{2}$ para o ribeiro da Mata da Margaraça ${ }^{2}$. Em ribeiros de plantações de eucalipto na Serra do Caramulo, a acumulação média anual de detritos foi avaliada em $3092 \mathrm{~g} / \mathrm{m}^{2}$, em grande parte devido à maior entrada de detritos no verão, quando o caudal é menor ${ }^{1}$. O material lenhoso é o mais abundante constituindo mais de $60 \%$ da massa dos detritos acumulados, em parte devido à sua lenta decomposição ${ }^{2}$.
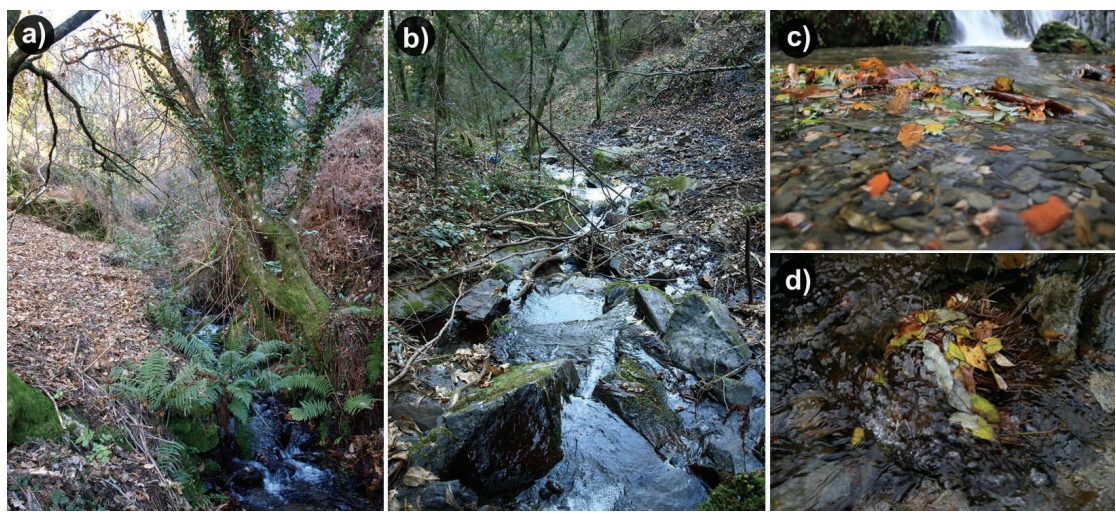

Figura 12.1. Ribeiros de floresta na Serra da Lousã: a) Ribeira do Candal e b) afluente da Ribeira do Catarredor. Pormenor de acumulação de folhas no leito de ribeiros: c) Fraga da Pena (Serra do Açor) e d) Ribeira do Candal. Fotografias: Verónica Ferreira e José Castela.

\section{Decomposição de folhas}

Uma vez que os ribeiros de floresta são ensombrados, a produção primária autóctone é reduzida, pelo menos durante parte do ano, pelo que a via autotrófica de circulação de carbono e nutrientes (produtores primários $\rightarrow$ herbívoros $\rightarrow$ níveis tróficos mais altos) é limitada. Por outro lado, as folhas que entram nos 
ribeiros encerram em si grandes quantidades de energia na forma de carbono, contido essencialmente na composição da celulose e da lignina; as folhas são também fontes importantes de nutrientes como o azoto e o fósforo ${ }^{7}$. Assim, as folhas constituem uma base alimentar heterotrófica (folhas + decompositores microbianos $\rightarrow$ invertebrados fragmentadores $\rightarrow$ níveis tróficos mais altos). A decomposição das folhas nos ribeiros é um processo da maior relevância uma vez que determina a circulação de carbono e nutrientes com a sua conversão em biomassa animal.

\subsection{Método dos sacos de rede para determinação da taxa de decomposição de detritos vegetais}

O estudo da decomposição dos detritos vegetais em ribeiros de floresta iniciou-se na década de 1960, altura em que alguns investigadores se aperceberam do potencial dos detritos vegetais para a economia energética dos ribeiros de floresta onde a reduzida irradiação solar limita a produção primária; o primeiro estudo a abordar a decomposição de detritos vegetais em ribeiros em Portugal data de $1992^{8}$. Desde logo foi adotado o protocolo usado pelos investigadores que estudavam a decomposição de detritos em meio terrestre, e que consistia na utilização de sacos de rede (Figura 12.2a, b).

Em linhas gerais, uma quantidade pré-pesada de detritos é fechada em sacos de rede e estes são incubados no ribeiro de estudo (Figura 12.2c). O tipo de detrito (p.ex., folhas, ramos, pedaços de madeira) e a sua identidade depende do objetivo do estudo. Também o estado do detrito (p.ex., folhas verdes ou senescentes, folhas secas ao ar ou secas em estufa) pode variar em função do objetivo do estudo ou da abordagem experimental. Já os sacos de rede podem ter malha de diferentes tamanhos, dependendo do objetivo 
do estudo. Sacos de malha fina ( $\leq 0,5 \mathrm{~mm}$ de abertura) permitem avaliar a decomposição induzida pela comunidade microbiana uma vez que impedem a entrada dos macroinvertebrados, enquanto sacos de malha grossa ( $>0,5 \mathrm{~mm}$ de abertura) permitem avaliar a decomposição induzida pelas atividades conjuntas da comunidade microbiana e dos macroinvertebrados (Figura 12.2a, b). Após um determinado tempo de incubação, os sacos são recuperados, os detritos são secos e novamente pesados para determinação da massa remanescente. Os resultados são geralmente expressos como percentagem de massa remanescente: $\% M_{r}=M_{r} / M_{i} \times 100$, sendo $M_{r}$ a massa remanescente e $M_{i}$ a massa inicial (Figura 12.2d); caso a massa inicial e a massa remanescente não sejam determinadas nas mesmas condições (p.ex., a massa inicial pode ser determinada após secagem ao ar e a massa remanescente após secagem em estufa) há necessidade de determinar um fator conversão para a massa inicial (p.ex., massa inicial após secagem em estufa/massa inicial após secagem ao ar).

Tendo em conta a percentagem de massa remanescente e o tempo de incubação, estima-se a taxa de decomposição. Assumese geralmente que a decomposição dos detritos segue um modelo exponencial negativo: $\% \mathrm{M}_{\mathrm{r}}=100 \times \mathrm{e}^{-k \mathrm{t}}$, sendo $100 \mathrm{o}$ intercepto (= $\% \mathbf{M}_{\mathrm{r}}$ ao dia zero), $\mathrm{t}$ o tempo de incubação (dias) e $k$ a taxa de decomposição (numa base diária) (Figura 12.2d). No entanto, quando o tempo de incubação não é suficientemente longo para que os detritos atinjam fases avançadas da decomposição, quando a proporção de compostos recalcitrantes é maior e a decomposição mais lenta, a decomposição pode apresentar uma dinâmica linear: $\% \mathrm{M}_{\mathrm{r}}=k \times \mathrm{t}+100$. Caso existam diferenças na temperatura da água entre ribeiros, o tempo (t) nos modelos acima pode ser substituído pelo acúmulo da temperatura diária média à data da amostragem (graus-dia, ${ }^{\circ} \mathrm{C}$ ) e a taxa de decomposição $(k)$ será expressa numa base de graus-dia. 

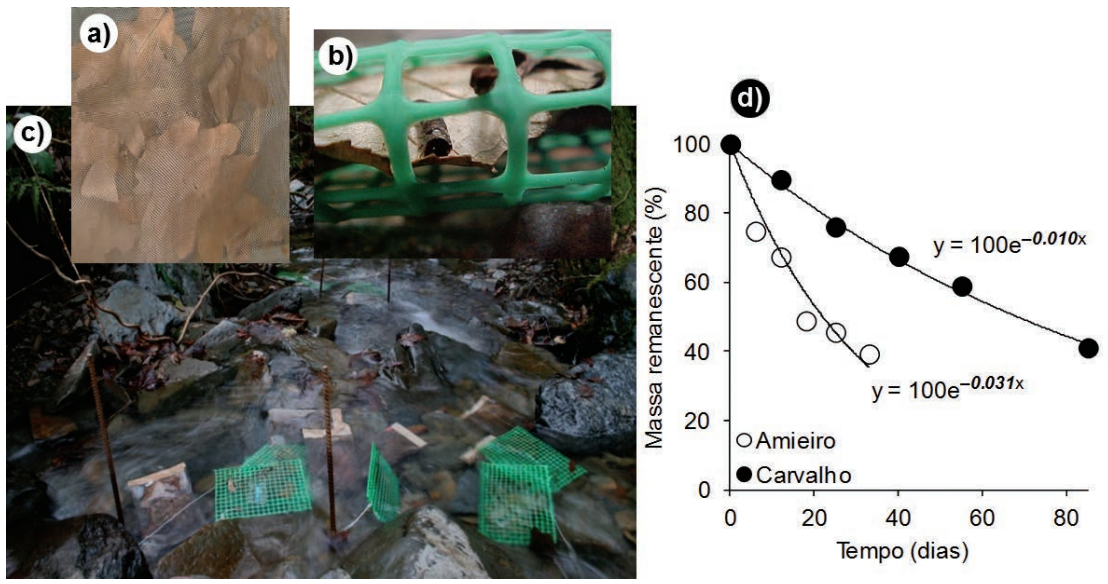

Figura 12.2. Sacos de rede a) de malha fina $(0,5 \mathrm{~mm}$ de abertura) e b) de malha grossa (10 $\mathrm{mm}$ de abertura). c) Incubação de sacos de rede com folhada na Ribeira do Candal (Serra da Lousã) no outono de 2006.

d) Percentagem de massa remanescente de folhas de amieiro (Alnus glutinosa) e de carvalho (Quercus robur) incubadas em sacos de malha grossa (10 $\mathrm{mm}$ de abertura) no ribeiro da Mata da Margaraça (Serra do Açor) no outono/inverno de 2003. Cada ponto representa a média de quatro amostras. É demonstrada a aplicação do modelo exponencial negativo para determinação das taxas de decomposição (em itálico) $\left(\mathrm{R}^{2}=0,93-0,99, \mathrm{p}<0,001\right)$. A decomposição de folhas de amieiro $(k=$ $0,031 /$ dia) é mais rápida que a decomposição de folhas de carvalho $(k=$ 0,010/dia). Fotografias: Verónica Ferreira.

\subsection{Fases da decomposição}

A decomposição das folhas que entram nos ribeiros decorre em três fases mais ou menos sobrepostas: (i) lixiviação; (ii) condicionamento microbiano; e (iii) fragmentação por invertebrados (Figura 12.3). A lixiviação consiste na perda de compostos hidrossolúveis como os polifenóis e os açúcares simples. Este processo ocorre desde que as folhas entram em contacto com a água e perdura durante todo o processo de decomposição, sendo no entanto mais intenso durante os primeiros dias de imersão9,10 (Figura 12.3). A perda de massa foliar por lixiviação durante os primei- 
ros dois dias de imersão pode atingir $20 \%$ da massa inicial ${ }^{11,12}$. A magnitude da lixiviação depende de fatores ambientais como a temperatura da água (é mais intensa a temperaturas mais altas) e das características das folhas como a dureza e a concentração de compostos hidrossolúveis? .

Pouco depois da imersão, mas principalmente após a redução da resistência da cutícula e a diminuição da concentração de compostos secundários (com atividade antimicrobiana como os polifenóis), as folhas são colonizadas por microorganismos decompositores ${ }^{13}$ (Figura 12.3). Os decompositores são essencialmente fungos e bactérias que produzem enzimas que maceram as folhas, incorporam o carbono foliar em biomassa (incluindo esporos reprodutores) e o mineralizam com a libertação de dióxido de carbono. O resultado da ação dos decompositores é a perda de massa foliar. A perda de massa foliar devido à atividade microbiana é substancial. Por exemplo, ao longo de um gradiente de perturbação no rio Ave a perda de massa foliar devido à atividade microbiana foi estimada em $35-53 \%$ da massa total perdida ${ }^{13}$. De salientar que as perdas de massa devidas à atividade microbiana podem representar até $100 \%$ da massa perdida devido à atividade biológica em casos onde a contribuição dos macroinvertebrados é negligenciável ${ }^{14-16}$.

A atividade dos microorganismos também leva à perda de massa foliar de maneira indireta, ao estimular a atividade dos invertebrados fragmentadores. A maceração enzimática das folhas pelos microorganismos torna-as mais macias e a acumulação de biomassa microbiana rica em nutrientes aumenta a qualidade nutritiva das folhas, o que as torna mais atrativas para os fragmentadores aquáticos que promovem a sua fragmentação ${ }^{10,17}$ (Figura 12.3). Está amplamente demonstrado que os fragmentadores preferem as folhas após estas terem sido condicionadas pelos microorganismos $^{18,19}$. Os fragmentadores aquáticos alimentam-se das folhas ou, no caso de algumas famílias de tricópteros, usam-nas na 
construção dos seus casulos 3,6 . O consumo anual de folhas pelo fragmentador Sericostoma vittatum (Tricoptera, Sericostomatidae) na Ribeira de São João (Serra da Lousã) foi estimado em 14-22 $\mathrm{g} / \mathrm{m}^{2}$ (dependendo da espécie de folha), quando a densidade e a biomassa média anual é de 115 indivíduos $/ \mathrm{m}^{2}$ e de $83 \mathrm{mg} / \mathrm{m}^{2}$, respectivamente, o que equivale a $2-4$ vezes a acumulação média anual de detritos no leito ${ }^{6}$. Já a fragmentação anual de folhas pelo fragmentador Lepidostoma hirtum (Tricoptera, Lepidostomatidae) para consumo e construção do casulo na Ribeira de São João foi estimada em $54 \mathrm{~g} / \mathrm{m}^{2}$, quando a densidade média anual é de 138 indivíduos $/ \mathrm{m}^{2}$, o que equivale a 7 vezes a acumulação média anual de detritos no leito ${ }^{3}$. A atividade dos fragmentadores sobre as folhas leva também à libertação de partículas orgânicas finas (incluindo fezes) que são usadas como recurso alimentar pelos invertebrados filtradores e coletores.

A fragmentação das folhas pode também resultar da abrasão física promovida pela corrente e sedimentos em transporte 20 . A abrasão física tem provavelmente pouca importância durante o verão, quando o caudal é mais baixo, mas pode estimular a perda de massa das folhas durante o inverno, quando a velocidade da corrente aumenta e é espectável um aumento da quantidade de sedimentos em transporte ${ }^{20}$.

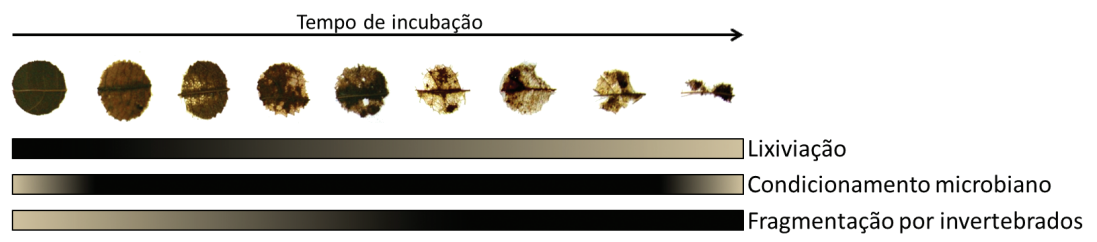

Figura 12.3. Representação esquemática da decomposição de folhas em ribeiros. As barras horizontais indicam a intensidade das três fases em que se divide a decomposição (notar a sua sobreposição): lixiviação, condicionamento microbiano e fragmentação. Cor mais carregada indica maior intensidade. Fotografias: Verónica Ferreira. 


\subsection{Decompositores microbianos}

As folhas em decomposição são colonizadas por uma grande variedade de microorganismos aquáticos (Capítulo 5). De entre eles, os fungos, principalmente os hifomicetes aquáticos, são considerados os principais decompositores ${ }^{13,16,21}$. De facto, em quatro locais ao longo de um gradiente de degradação no rio Ave, os fungos aquáticos contribuíram para $74-90 \%$ da massa perdida devido à atividade microbiana enquanto as bactérias contribuíram para 10-26\%, i.e., 3-9 vezes menos ${ }^{13}$. A atividade reprodutiva dos hifomicetes aquáticos, i.e., a produção de esporos (Figura $12.4 \mathrm{a}-\mathrm{c}$ ), incorporou até $7 \%$ da massa inicial de folhas de carvalho incubadas durante 85 dias no ribeiro da Mata da Margaraça ${ }^{22}$, até $10 \%$ da massa inicial de folhas de carvalho incubadas durante 63 dias na Ribeira do Botão ${ }^{23}$ e até $10 \%$ da massa inicial de folhas de eucalipto incubadas durante 90 dias no mesmo ribeiro ${ }^{24}$. No entanto, a maior parte da massa das folhas é convertida em micélio (biomassa fúngica) ou é mineralizada 25,26.

A atividade dos microorganismos (i.e., a sua respiração, crescimento e reprodução) nas folhas inicia-se logo após a colonização, até um pico $^{15,17,21,27,28}$ (Figura 12.4d) cuja magnitude e tempo que demora a ser atingido dependem da identidade das folhas e das condições ambientais (p.ex., temperatura, concentração de nutrientes, presença de contaminantes), sendo geralmente mais elevado e rápido para folhas moles e ricas em nutrientes (p.ex., folhas de amieiro) e quando a concentração de nutrientes na água é moderada15,17,22 (Figura 12.4d). 

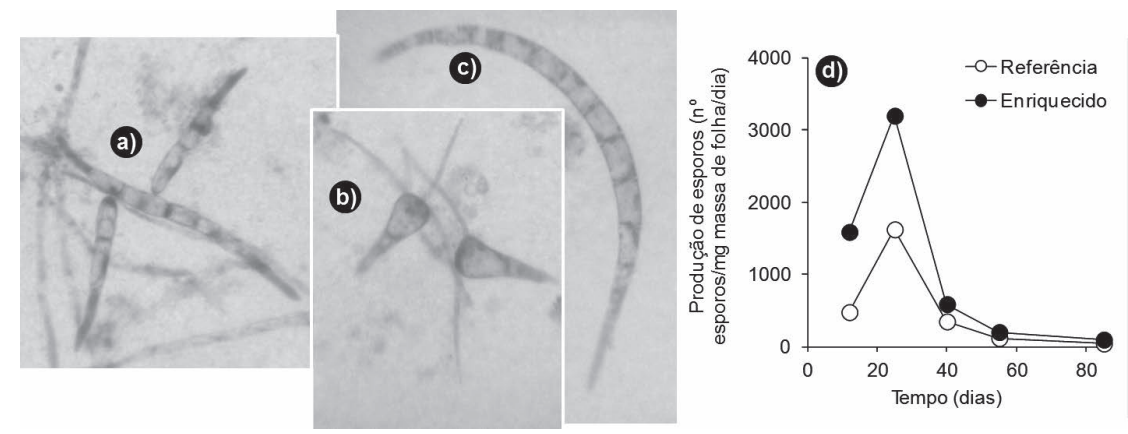

Figura 12.4. Esporos de hifomicetes aquáticos: a) Tricladium splendens; b) Clavariopsis aquatica; c) Anguillospora crassa; os esporos são estruturas microscópicas e não estão à escala. d) Dinâmica de produção de esporos por hifomicetes aquáticos associados a folhas de carvalho Quercus robur incubadas num local de referência ( $82 \mu \mathrm{g}$ azoto/L) e num local enriquecido em nutrientes (500 $\mu \mathrm{g}$ azoto/L) no ribeiro da Mata da

Margaraça no outono/inverno de 2003. Fotografias: Verónica Ferreira.

\subsection{Invertebrados fragmentadores}

De entre os macroinvertebrados que habitam os ribeiros (Capítulo 7), os fragmentadores são os que mais diretamente contribuem para a decomposição das folhas (Figura 12.5). Nos ribeiros de floresta no centro e norte de Portugal, os fragmentadores são na sua maioria larvas e ninfas de insetos pertencentes às ordens Tricoptera e Plecoptera, respetivamente, e têm os seus ciclos de vida sincronizados com a queda de folhas que ocorre no outono ${ }^{3,6}$. Em linhas gerais, os juvenis eclodem dos ovos no final do verão e as jovens larvas e ninfas, ainda com um aparelho bocal imaturo, começam por ser coletoras (i.e., alimentam-se de partículas orgânicas finas que recolhem do sedimento). À medida que as larvas e ninfas crescem o seu aparelho bocal torna-se mais robusto e passam a alimentar-se de folhas e outras partículas orgânicas grosseiras, o que coincide com a queda das folhas no outono/inverno. As larvas e ninfas vão crescendo até à primavera alimentando-se de folhas. Na primavera, a 
quantidade de alimento disponível começa a diminuir, a temperatura da água aumenta e as larvas e ninfas sofrem metamorfose e emergem como adultos alados para uma curta fase de vida adulta. Enquanto adultos, os insetos não se afastam dos ribeiros e após o acasalamento as fêmeas depositam os ovos em meio aquático. Estes incubam até à eclosão dos juvenis no final do verão e o ciclo recomeça.

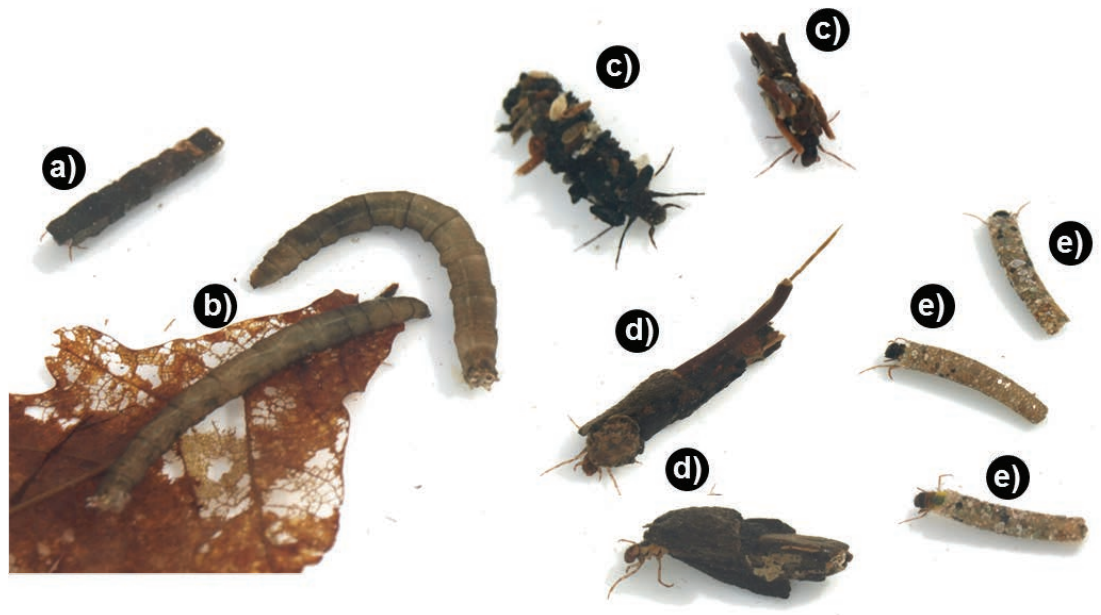

Figura 12.5. Fragmentadores típicos de ribeiros do centro de Portugal: a) Lepidostoma hirtum; b) Tipula sp.; c) Limnephilidae; d) Calamoceras marsupus; e) Sericostoma vittatum. Fotografias: Andreia Ferreira.

3. Fatores que a afetam a decomposição e sensibilidade a alterações ambientais induzidas pelas atividades humanas

Há vários fatores que afetam a taxa a que as folhas se decompõem (Figura 12.6). Estes podem estar relacionados com a qualidade das folhas, i.e., as suas características físicas como a dureza e a espessura da cutícula, e químicas como a concentração de compostos secundários (p.ex., óleos e polifenóis), compostos estruturais (p.ex., lignina e celulose) e nutrientes (p.ex., azoto e fósforo) ${ }^{7,29}$. Folhas 
mais duras e pobres em nutrientes decompõem-se mais lentamente do que folhas mais moles e ricas em nutrientes, sendo a concentração de lignina (muitas vezes correlacionada com a dureza) geralmente mais determinante que a concentração de nutrientes ${ }^{7,15}$.

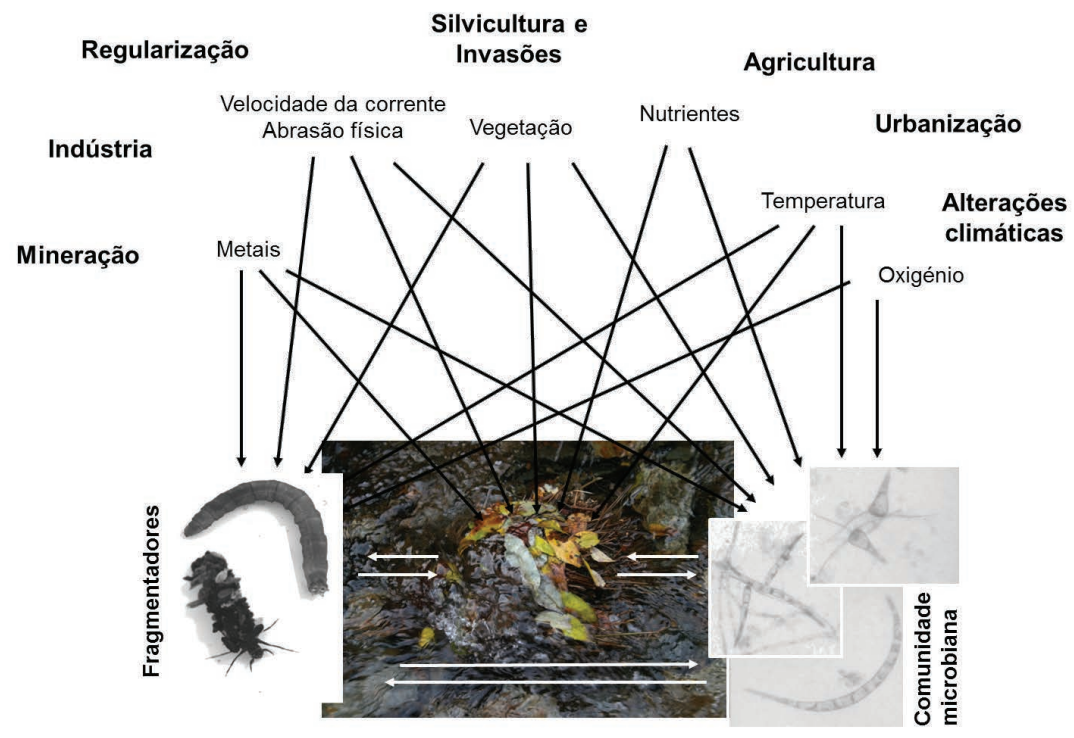

Figura 12.6. Representação esquemática de alguns fatores que afetam a decomposição das folhas diretamente ou por via de efeitos nas comunidades aquáticas. Atividades humanas que podem induzir alterações nas variáveis ambientais são apresentadas a negrito. Fotografias: Andreia Ferreira, José Castela e Verónica Ferreira.

Uma vez que a qualidade das folhas depende da sua identidade, alterações na composição da floresta que resultem em alterações na identidade das folhas que entram nos ribeiros podem afetar a sua decomposição ${ }^{30}$. Alterações da floresta podem afetar a decomposição das folhas também por via da alteração das condições ambientais e das comunidades aquáticas ${ }^{11,30,31}$. De facto, foi encontrada uma correlação positiva entre o número de espécies arbóreas na zona ripária de ribeiros de floresta caducifólia nativa da Serra da Lousã e do Caramulo e o número de espécies de hifomicetes aquáticos, o número de espé- 
cies de macroinvertebrados e a taxa de decomposição de folhas de carvalho ${ }^{4}$. Quando ocorre a substituição de floresta caducifólia mista por plantações de eucalipto verifica-se também uma redução da taxa de decomposição das folhas, principalmente em ambientes mais áridos onde os ribeiros de eucaliptal acabam por secar durante a estação mais quente, grandemente em consequência da redução no número de espécies e abundância de macroinvertebrados fragmentadores ${ }^{31}$.

A concentração de nutrientes na água é também um fator determinante da taxa de decomposição das folhas. As folhas são em geral pobres em nutrientes (azoto e fósforo) o que limita a utilização do carbono orgânico por parte dos decompositores que têm que manter um certo balanço entre azoto, fósforo e carbono na sua biomassa. No entanto, os microorganismos decompositores têm a capacidade de retirar nutrientes da água, onde se encontram na forma inorgânica e pronta a assimilar. Assim, um aumento da disponibilidade de nutrientes na água geralmente estimula a atividade dos decompositores e a utilização de carbono orgânico o que se traduz numa estimulação da taxa de decomposição ${ }^{17,22}$. A taxa de decomposição das folhas pode, no entanto, diminuir em ribeiros com concentrações de nutrientes muito altas se estas ocorrerem simultaneamente com uma diminuição na concentração de oxigénio ou aumento da sedimentação como pode acontecer em áreas fortemente urbanizadas ou sujeitas a agricultura intensiva ${ }^{13,32}$.

A temperatura da água é outro fator determinante das taxas de lixiviação, atividade dos organismos aquáticos e decomposição. $\mathrm{O}$ aumento da temperatura (até ao ótimo térmico dos organismos) estimula a atividade dos organismos aquáticos o que pode acelerar a taxa de decomposição das folhas. Isto explica os valores de decomposição mais elevados no verão quando comparado com estações mais frias ${ }^{20,28}$. O efeito do aumento da temperatura em resultado de atividades humanas neste processo é mais difícil de antecipar devido à covariação entre fatores ambientais. Por exemplo, o potencial efeito 
estimulador do aumento da temperatura na atividade dos decompositores e consequentemente na taxa de decomposição das folhas pode ser refreado caso a concentração de nutrientes dissolvidos seja baixa ${ }^{28}$.

\subsection{Uma experiência de fertilização in situ}

Uma vez que a atividade microbiana é limitada em ribeiros oligotróficos, a taxa de decomposição das folhas é geralmente mais rápida em ribeiros com concentrações moderadas de nutrientes (p.ex., ribeiros em zonas agrícolas) ${ }^{17,32}$. No entanto, diferenças nas taxas de decomposição das folhas entre ribeiros podem ser devidas não só a diferenças na concentração de nutrientes dissolvidos mas também a outras diferenças que possam existir nas características da água ou da vegetação ripária por exemplo. Assim, a melhor maneira de avaliar o efeito do aumento da concentração de nutrientes na decomposição das folhas, mantendo o realismo das condições de campo, é efetuando uma manipulação de nutrientes ao nível do ribeiro e comparando locais fertilizados com locais não fertilizados.

No outono/inverno de 2003 foi promovida a fertilização do ribeiro da Mata da Margaraça (Serra do Açor) pela adição de uma solução de nitrato de sódio $\left(\mathrm{NaNO}_{3}\right)$ num ponto do ribeiro (N1) ${ }^{22}$ (Figura $12.7 \mathrm{a}, \mathrm{b}$ ). A adição de nutrientes foi feita continuamente ao longo de quatro meses (outubro 2003 - janeiro 2004), e o consumo biológico de azoto gerou um gradiente de azoto dissolvido ao longo de $255 \mathrm{~m}$ para jusante do ponto de adição (locais N1 N4: 983-214 $\mu$ g azoto/L); o local de referência (R) localizava-se 55 $\mathrm{m}$ a montante do ponto de adição de nutrientes $(82 \mu \mathrm{g}$ azoto/L) (Figura 12.7c). Folhas de amieiro (moles e ricas em nutrientes) e de carvalho (mais duras e pobres em nutrientes) foram incubadas em sacos de malha grossa (10 $\mathrm{mm}$ de abertura) ao longo deste gradiente de azoto para determinação da taxa de decomposição. 
A experiência de decomposição foi repetida em todos os locais no outono/inverno de 2004, sem que houvesse fertilização.

As taxas de decomposição e as atividades reprodutivas (i.e., produção de esporos) dos hifomicetes aquáticos associados às folhas foram estimuladas com o aumento da concentração de azoto, de acordo com um modelo do tipo Michaelis-Menten (Figura $12.7 \mathrm{~d}$, e). A saturação das taxas de decomposição e das atividades reprodutivas ocorreu a uma concentração de azoto relativamente baixa $\left(\mathrm{K}_{\mathrm{m}} \leq 52 \mu \mathrm{g}\right.$ azoto/L e $\leq 232 \mu \mathrm{g}$ azoto/L, respetivamente; Figura $12.7 \mathrm{~d}$, e). Isto sugere que tanto as taxas de decomposição como as atividades reprodutivas dos hifomicetes aquáticos são muito sensíveis a alterações na concentração de azoto na água ${ }^{22}$.
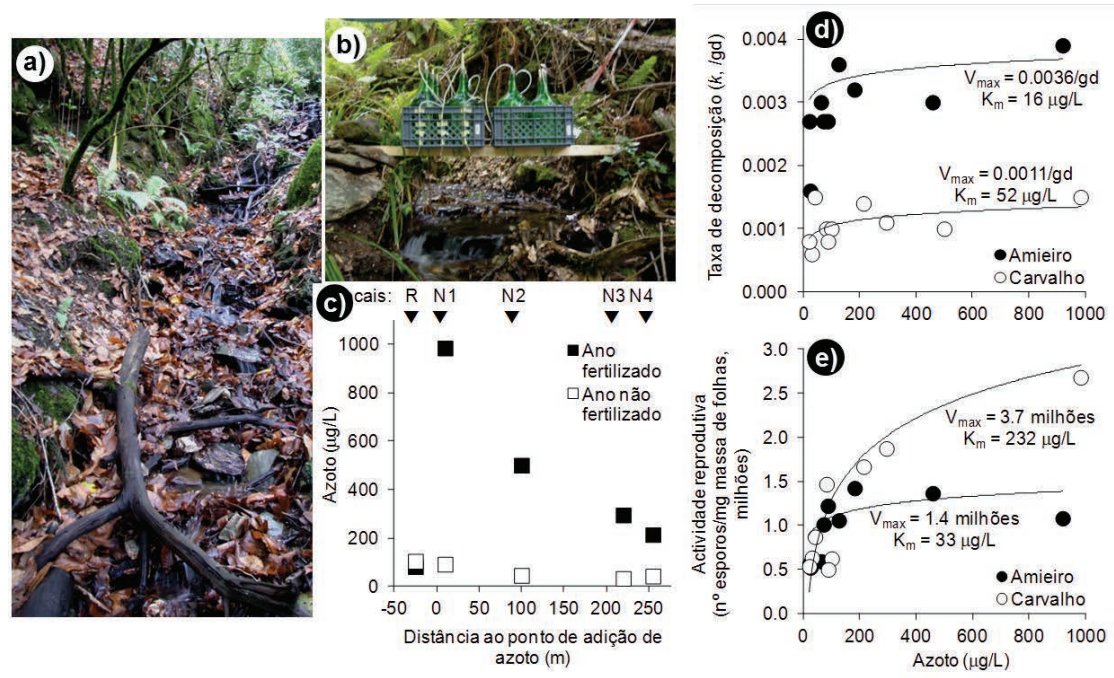

Figura 12.7. a) Ribeiro da Mata da Margaraça, outono de 2003. b) Aparato de fertilização constituído por garrafas com a solução de $\mathrm{NaNO}_{3}$. c) Concentração de azoto nos locais de estudo no ano fertilizado e no ano não fertilizado. d) Relação entre as taxas de decomposição (em graus-dia) e a concentração de azoto na água. e) Relação entre a atividade reprodutiva de hifomicetes aquáticos e a concentração de azoto na água. Um modelo do tipo Michaelis-Menten foi aplicado aos dados: $\mathrm{V}=\left(\mathrm{V}_{\max } \times[\mathrm{S}]\right) /\left(\mathrm{K}_{\mathrm{m}}+[\mathrm{S}]\right)$, sendo $\mathrm{V}_{\max } \mathrm{o}$ valor máximo, $\mathrm{K}_{\mathrm{m}}$ a concentração de azoto à qual é atingido metade do valor máximo e [S] a concentração de azoto; os valores de $\mathrm{V}_{\max }$ e $\mathrm{K}_{\mathrm{m}}$ são apresentados $\left(\mathrm{R}^{2}=0,51-0,92, \mathrm{p}<0,001\right)$. Fotografias: Verónica Ferreira. 


\subsection{Uma experiência de aquecimento in situ}

Os estudos sobre os efeitos do aumento da temperatura na estrutura das comunidades e no funcionamento dos ribeiros têm sido numerosos e adquiriram relevância acrescida face à problemática do aquecimento global33 e à intensificação de atividades humanas como a desflorestação e a urbanização ${ }^{34}$. Para avaliar os efeitos do aquecimento nas comunidades e processos aquáticos, integrando os diferentes níveis de organização biológica e as variações ambientais (diárias e sazonais) naturais de um ribeiro, foi manipulada a temperatura da água num ribeiro de floresta 35 .

Para tal, foi implementado na Ribeira do Candal (Serra da Lousã) um sistema integrado de controlo do fluxo de água e de aquecimento, com vista ao aumento da temperatura da água em $3^{\circ} \mathrm{C}$ (Figura 12.8) 35 . Este aquecimento baseou-se em modelos climáticos para a zona centro de Portugal ${ }^{36}$ e na estreita relação entre temperatura do ar e da água de pequenos ribeiros (incremento de $0,6^{\circ} \mathrm{C}$ por cada grau de aumento de temperatura do $\mathrm{ar}^{37}$ ). Os trabalhos sugerem que o aumento da temperatura resulta no aumento da massa dos biofilmes autotróficos (i.e., compostos por microalgas), na modificação da sua composição e na alteração da sua capacidade de utilização da matéria orgânica e do seu valor como fonte nutritiva para as cadeias alimentares autotróficas 38,39 .

O efeito do aquecimento nas atividades biológicas parece ser mais marcante na estação fria. Tal como acontece com os biofilmes, no inverno, altura em que a temperatura é limitante, observa-se uma estimulação da atividade dos decompositores microbianos e, consequentemente, da degradação foliar 14,28. Este efeito na atividade microbiana parece nem sempre ser acompanhado de acréscimo de biomassa, atividade reprodutiva 
ou alterações na estrutura da comunidade 21,28 . Incrementos de $3^{\circ} \mathrm{C}$ parecem não afetar a abundância dos fragmentadores, mas estimulam a sua atividade e consequentemente a degradação de folhas, sobretudo as mais recalcitrantes, como o carvalho ${ }^{10,14,40}$. Uma maior taxa de consumo de folhas por fragmentadores com o aumento da temperatura poderá dever-se a uma melhor qualidade foliar (mediada pelas atividades fúngicas) e/ou a maiores necessidades energéticas dos fragmentadores para completar rapidamente o seu ciclo de vida (em vez de alocar energia para a produção de biomassa ${ }^{40}$.

Assim, o aquecimento global pode resultar numa redução na eficiência de retenção do carbono em pequenos rios. Pode também ocorrer uma diminuição rápida da matéria orgânica disponível para as teias alimentares baseadas em detritos, com importantes efeitos no ciclo de carbono e teias alimentares aquáticas e terrestres $^{41}$. 

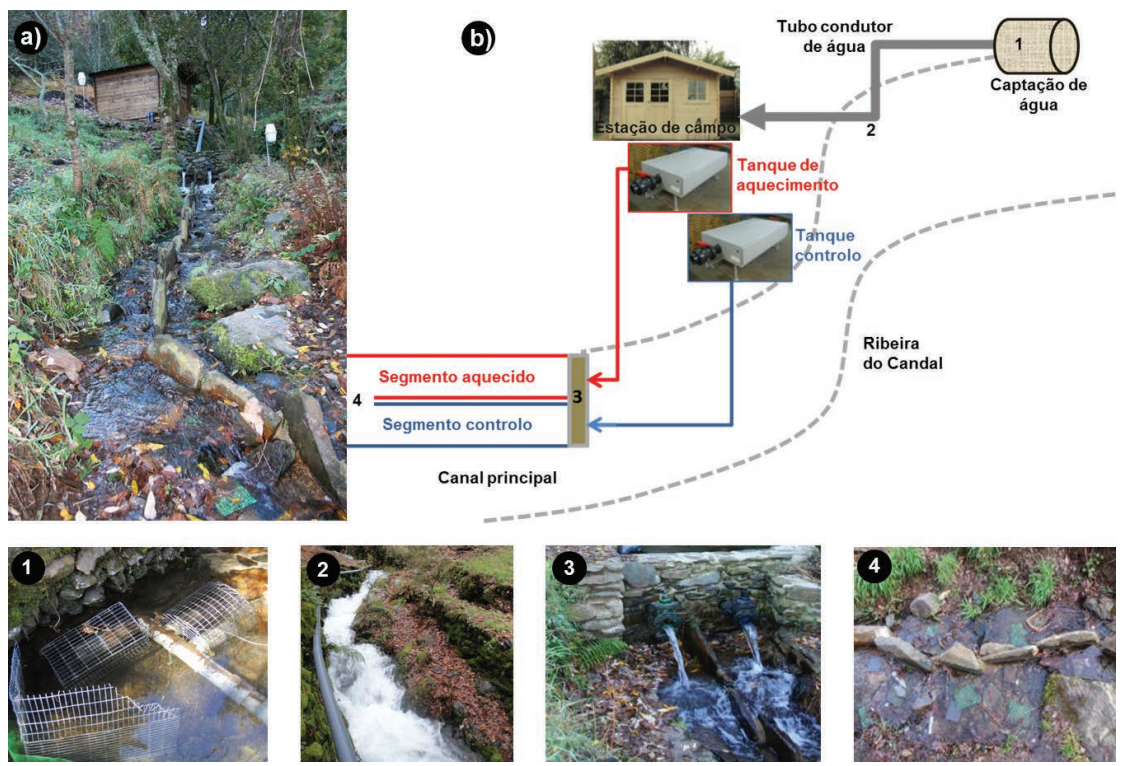

Figura 12.8. a) Ribeira do Candal, Serra da Lousã. b) Esquema do sistema hidráulico e de aquecimento. Uma divergência natural ( $22 \mathrm{~m})$ da ribeira foi dividida ao meio com rocha local (xisto). As metades - segmento aquecido e segmento controlo - passaram a receber água $(3 \mathrm{~L} / \mathrm{s})$ diretamente de dois tanques de aço inoxidável (260 L de capacidade), o tanque de aquecimento e o tanque controlo, respetivamente. Estes tanques foram alimentados pela água do ribeiro que foi transportada, por gravidade, até à estação de campo onde se localizavam os tanques. O curso de água principal manteve-se inalterado garantindo o escoamento da maior parte $\mathrm{da}$ água. $\mathrm{O}$ aumento de temperatura no segmento aquecido $\left(\sim 3^{\circ} \mathrm{C}\right.$ acima

da temperatura ambiente) foi realizado pelo tanque de aquecimento com o auxílio de 30 resistências $(2000 \mathrm{~W})$ alimentadas por uma potência elétrica constante de 41,4 kVA. O tanque controlo não foi equipado com resistências para aquecimento. Fotografias: João Rosa e Cristina Canhoto.

\section{Decomposição de folhas como indicador de qualidade ambiental}

De acordo com a Diretiva Quadro da Água ${ }^{42}$, é obrigatório que os estados membros da União Europeia passem a monitorizar a qualidade das suas águas. Apesar de a legislação mencionar 
parâmetros funcionais, a Diretiva assenta essencialmente em parâmetros estruturais biológicos (i.e., número e tipo de espécies).

Uma vez que a decomposição de folhas é um processo biológico em que intervém uma variedade de organismos (bactérias, fungos, invertebrados) sensíveis a variações no ambiente, foi proposto que alterações nas taxas de decomposição possam ser indicadoras de alterações na qualidade do ambiente ${ }^{43}$. Com efeito, em rios do centro de Portugal (principalmente nas Serras do Caramulo e da Lousã), foi demonstrado que as taxas de decomposição respondem de forma previsível e consistente a alterações na floresta e muito particularmente às plantações com eucaliptos (inibição) ${ }^{31,44}$ e ao aumento na quantidade de nutrientes na água (estimulação)17,22,23. Assim, as taxas de decomposição de substratos vegetais padronizados podem ser um bom indicador funcional de perturbações ambientais. No entanto, a grande variação natural nas taxas de decomposição tem que ser considerada, assim como as situações sob múltiplas perturbações uma vez que algumas perturbações aceleram as taxas de decomposição enquanto outras causam inibição (Figura 12.9).

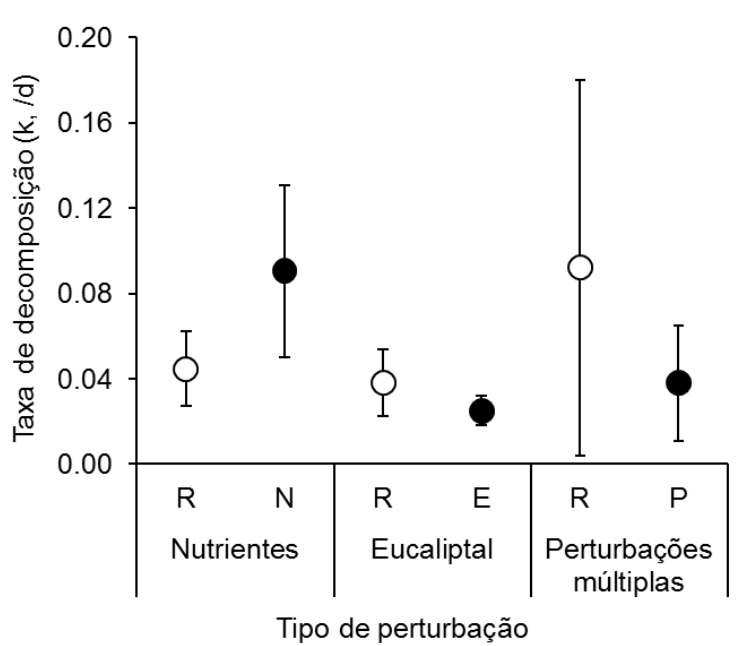

Figura 12.9. Taxas de decomposição de folhas de amieiro em ribeiros de referência $(\mathrm{R}$, círculos brancos) e ribeiros sujeitos a três tipos de perturbações (círculos pretos): $\mathrm{N}$, ribeiros enriquecidos em nutrientes ${ }^{17}$; E, ribeiros em eucaliptal ${ }^{31}$; $\mathrm{P}$, ribeiros sujeitos a perturbações múltiplas 45 . Os valores representam a média para cada condição e as linhas o 'desvio padrão', i.e., a variação dos valores relativamente ao valor médio calculado. 


\section{Produção primária}

Nos ecossistemas lóticos, os seres autotróficos, como as algas, as cianobactérias, os briófitos e os macrófitos, captam a energia solar para conduzir os seus processos metabólicos e produzir nova biomassa. Esta nova matéria orgânica fica assim disponível no sistema e irá constituir uma fonte importante de carbono e energia para os seres vivos heterotróficos ${ }^{46}$. Da energia captada pelos organismos autotróficos nem toda é usada para a produção de biomassa, uma vez que parte dessa energia é gasta na respiração celular. Por isso, devemos distinguir entre produtividade primária grosseira (PPG), que corresponde à taxa de produção de matéria orgânica a partir de fontes de carbono inorgânico durante a fotossíntese, e produtividade primária líquida (PPL) que equivale à matéria orgânica efetivamente armazenada depois de descontada a matéria orgânica gasta na respiração celular para a obtenção de energia ${ }^{47}$.

A produção primária em sistemas lóticos pode variar entre rios em função das características fluviais e ribeirinhas. Na bacia do rio Quarteira (Sul de Portugal), as taxas metabólicas eram subestimadas ou sobrestimadas quando se extrapolavam os resultados do metabolismo de um determinado tipo de habitat para um troço ou para um ribeiro ${ }^{48}$. Por isso, a caracterização dos processos metabólicos, nomeadamente da produção primária, requer a cobertura dos diferentes tipos de habitat tendo em conta a proporção relativa e a escala apropriada ${ }^{48}$. Contudo, a informação disponível sobre metabolismo, e particularmente sobre produtividade primária, é bastante escassa em rios e ribeiros em Portugal.

Entre os fatores que mais podem influenciar as taxas de produção primária, salientam-se (i) a disponibilidade em luz, que pode ser influenciada pela profundidade da água, pela turbidez e carga de sedimentos em suspensão e pela sombra proveniente da vegetação ribeirinha ${ }^{46}$, (ii) a disponibilidade em nutrientes, nomeadamente nas 
suas formas assimiláveis nitrato, amónia e fosfato solúvel ${ }^{49}$ e (iii) a dinâmica das comunidades biológicas, incluindo a composição e a abundância dos produtores primários, a competição, a herbivoria ${ }^{50}$ e a presença de distúrbios externos de natureza físico-química que podem alterar a estrutura e a atividade das comunidades (p.ex., contaminação por metais ${ }^{51}$, eventos de cheias $^{52}$ ).

A biomassa de biofilmes (constituídos por algas, bactérias e fungos embebidos numa matriz) formados sobre pedras e calhaus de pequenos ribeiros florestados, onde a luz é um fator limitante, pode ser máxima no outono ${ }^{2}$. Apesar dos dias serem mais curtos do que no verão e da intensidade da luz ser também menor, a disponibilidade em luz pode aumentar durante o período de queda da folha, tal como observado na Mata da Margaraça ${ }^{2}$.

Numa experiência in situ conduzida na bacia hidrográfica rio Ave (norte de Portugal) ao longo de um gradiente de eutrofização, verificou-se que, quando os nutrientes eram limitantes, a biomassa e a produtividade dos produtores primários, nomeadamente das algas bentónicas, aumentava com o aumento moderado da concentração de nutrientes, mas diminuía como resposta a níveis de nutrientes mais elevados porque a eutrofização leva à diminuição do nível de oxigénio e à presença de outros agentes de stress que se sobrepõem ao efeito estimulante dos nutrientes ${ }^{49}$. O padrão de resposta foi semelhante ao observado no processo ecológico complementar de decomposição ${ }^{49,53}$.

Por outro lado, a atividade fotossintética é afetada pela temperatura do sistema, da qual depende o metabolismo de todos os seres vivos. Numa experiência de manipulação da temperatura in situ, o aumento de $3^{\circ} \mathrm{C}$ face à temperatura ambiente estimulou a densidade de diatomáceas e a sua biomassa quantificada pela concentração de clorofila ${ }^{54}$. Este estímulo foi particularmente notório nos meses mais frios, com possíveis implicações para o metabolismo do rio. 
No centro de Portugal, verificou-se que a respiração das algas bentónicas era estimulada pelo aumento da temperatura, mais do que pelo aumento da concentração de nutrientes ${ }^{55}$. Na primavera, o aumento simultâneo da temperatura e da concentração de nutrientes estimulou a respiração das algas em maior extensão do que o previsto a partir do efeito individual de cada fator, contribuindo assim para acentuar o nível da libertação de $\mathrm{CO}_{2}$ para a atmosfera intensificando o potencial efeito de estufa ${ }^{55}$. Contudo, este estudo não providenciou informação sobre os efeitos na produtividade primária ou na atividade fotossintética.

\section{Produção secundária}

Os 'consumidores' são organismos que se alimentam de outros organismos. A energia ingerida e assimilada pelos consumidores é utilizada em três processos fundamentais: manutenção, reprodução e investimento em novos tecidos. Ao nível do ecossistema, a 'produção secundária' é a geração de novos tecidos (em termos de peso, carbono ou unidades energéticas) por um consumidor. Quando esta produção é expressa por unidade de área e tempo (geralmente 1 ano) referimo-nos a 'produtividade'. Valores elevados de produtividade indicam que grande parte da energia que está num nível trófico passa rapidamente ao nível trófico seguinte. Os consumidores nos rios são os animais (vertebrados ou invertebrados), os fungos e as bactérias. Organismos de grandes dimensões têm em geral uma produção baixa e, em sentido contrário, organismos de pequenas dimensões são capazes de crescer muito rapidamente e duplicar a sua massa em pouco tempo.

Os estudos de produtividade secundária em rios de Portugal são escassos. Valores de produção muito elevados foram referidos para o lagostim-vermelho da Luisiana (Procambarus clarkii) no período 
em que invadiu o baixo Mondego (Tabela 12.1.). Valores muito mais baixos foram registados para insetos aquáticos em pequenos rios (Tabela 12.1.). Embora a produtividade seja calculada numa base anual, os valores variam ao longo do ano. Por exemplo, para as larvas de tricóptero Sericostoma vittatum, na Ribeira de São João (Serra da Lousã), valores mais elevados de produção foram registados na primavera, quando os animais eram de maiores dimensões e as temperaturas altas. No verão, a maior parte dos indivíduos na ribeira eram de pequenas dimensões (biomassa baixa) e, por isso, a produção foi baixa ${ }^{6}$.

Pouco sabemos sobre a produção dos hifomicetes aquáticos em condições naturais. Pascoal \& Cássio ${ }^{13}$ e Pascoal et al. ${ }^{16}$ mediram a produtividade de hifomicetes de folhas recolhidas em rios e referiram valores de 2,0 a 9,5 mg de carbono/g de carbono de folha/ dia. Assumindo um valor de $46 \%$ de carbono em detritos foliares (valor médio de 177 amostras de folhas de 151 espécies de árvores de 24 regiões distribuídas pelo globo), $42 \%$ de carbono em fungos aquáticos ${ }^{56}$ e um valor médio de $36 \mathrm{~g}$ de material orgânico/ $\mathrm{m}^{2} 6$, o valor calculado de produção para os hifomicetes aquáticos seria de 28,8 a $136,4 \mathrm{mg}$ de fungos/ $\mathrm{m}^{2} /$ ano, um valor mais baixo do que o observado para invertebrados e peixes.

Tabela 12.1.

Valores de produção secundária $\left(\mathrm{g} / \mathrm{m}^{2} / \mathrm{ano}\right)$ de alguns consumidores em rios de Portugal.

\begin{tabular}{llll}
\hline Nome comum & Nome científico & Local & Produtividade \\
\hline${ }^{1}$ Lagostim-vermelho & Procambarus clarkii & Baixo Mondego & 27,22 \\
${ }^{2}$ Gambúsia (peixe) & Gambusia holbrooki & Baixo Mondego & 3,10 \\
${ }^{3}$ Tricóptero (insecto) & Lepidostoma hirtum & $\begin{array}{l}\text { Ribeira São João, } \\
\text { Serra da Lousã }\end{array}$ & 0,06 \\
4Tricóptero (insecto) & Sericostoma vittatum & $\begin{array}{l}\text { Ribeira São João, } \\
\text { Serra da Lousã }\end{array}$ & 0,44 \\
\hline
\end{tabular}

1, Anastácio \& Marques ${ }^{57} ; 2$, Cabral \& Marques ${ }^{58}$; 3, Azevedo-Pereira et al. ${ }^{3} ; 4$, González \& Graça ${ }^{6}$. 


\section{Serviços prestados pelos ecossistemas fluviais}

'Serviços dos ecossistemas' é uma expressão que traduz o conjunto de benefícios prestados pelos ecossistemas às sociedades humanas ${ }^{59}$. Muitos são determinantes para a sua sobrevivência (p.ex., água de boa qualidade para consumo) enquanto outros aumentam a sua qualidade de vida (p.ex., valores estéticos). Os serviços dos ecossistemas (fluviais) são múltiplos e podem classificar-se em quatro categorias (Tabela 12.2.). Estes serviços dependem dos processos que ocorrem nos ecossistemas; p.ex., a purificação da água depende de processos como a retenção e degradação da matéria orgânica, desnitrificação, fotossíntese e, no caso da presença de contaminantes (sensu lato), da sua remoção biológica $^{60-62}$.

Tabela 12.2.

Serviços prestados pelos cursos de água. Cada serviço é garantido por um ou mais processos. Principais fontes: MEA ${ }^{59}$, Acuña et al. ${ }^{60}$, Harrison et al. ${ }^{61}$, Palmer \& Richardson ${ }^{62}$, Brauman et al. ${ }^{63}$, Sabater ${ }^{64}$.

\begin{tabular}{ll}
\hline Tipo de serviço & Exemplos \\
\hline $\begin{array}{l}\text { Provisionamento } \\
\text { (i.e., serviços de fornecimento de } \\
\text { bens ou produtos) }\end{array}$ & $\begin{array}{l}\text { Água para consumo e irrigação } \\
\text { Biodiversidade } \\
\text { Produtos naturais com utilidade medicinal } \\
\text { Produção de alimento } \\
\text { Produção de energia } \\
\text { Begulação } \\
\text { (i.e., benefícios não-materiais) }\end{array}$ \\
& $\begin{array}{l}\text { Decomposição de matéria orgânica } \\
\text { Dispersão de sementes }\end{array}$ \\
& Diversidade genética \\
& Manutenção de habitats \\
& Purificação da água/Tratamento de resíduos \\
& $\begin{array}{l}\text { Regulação da erosão e transporte de sedimentos } \\
\text { Regulação de perturbações hidrológicas }\end{array}$ \\
\hline
\end{tabular}




\begin{tabular}{ll}
\hline Tipo de serviço & Exemplos \\
\hline & Regulação do clima \\
& Saúde humana \\
& Sequestração de carbono e azoto \\
Suporte & Biodiversidade \\
(i.e., necessários à efetivação dos & Produção primária \\
outros serviços) & Reciclagem de nutrientes \\
Culturais & Educacionais \\
& Espirituais e religiosos \\
& Estéticos \\
& Recreacionais e ecoturismo \\
\hline
\end{tabular}

De salientar o serviço prestado pela biodiversidade já que todas as categorias tendem a incluir componentes de biodiversidade ou a ser afetadas por ela ${ }^{65}$. A sua importância transversal é facilmente compreensível no funcionamento de ribeiros florestados: uma elevada diversidade de decompositores ${ }^{66}$ e fragmentadores ${ }^{67}$ tende a estimular a degradação foliar contribuindo para uma maior eficácia na reciclagem de nutrientes (papel regulador) e a gerar água própria para consumo (serviço final). No entanto, é frequente a oposição entre a preservação da biodiversidade como serviço (visão conservacionista ${ }^{68}$ ) e outros benefícios (p.ex., energia hidroelétrica obtida através da construção de barragens ${ }^{69}$ ).

Nas últimas décadas, mais de $60 \%$ dos serviços ou benefícios sociais prestados pelos ecossistemas foram afetados pelas atividades humanas $^{70}$. Adicionalmente, fenómenos globais como a alteração do clima promovem a redução ou perda dos benefícios inerentes à capacidade de sequestração de carbono (regulação do clima ${ }^{71}$ ), regulação do fluxo, perdas de biodiversidade e serviços associados. Também, a invasão de espécies, sendo a invasão pelo mexilhão-zebra (Dreissena polymorpha) um exemplo icónico, leva a prejuízos em termos de serviços de provisionamento (p.ex., alimento para peixes), de regulação (p.ex., depuração da água) e mesmo culturais (p.ex., estética de embarcações) ${ }^{72}$. 
O conhecimento das funções e serviços dos ecossistemas fluviais é ainda limitado, pouco claro e/ou difícil de valorar. A relação íntima e assimétrica da maior parte da rede fluvial (i.e., os cursos de água de baixa ordem) com a sua bacia de drenagem, nomeadamente com as áreas ripárias, torna os serviços fluviais 'compartilhados' com outros ecossistemas (nomeadamente terrestres) e, portanto, de avaliação difícil. Urge encontrar indicadores dos serviços que sejam robustos, facilmente compreensíveis e aceites por investigadores, decisores ${ }^{73,74}$ e, se possível, pelo público em geral. A tradução em valor económico dos serviços dos ecossistemas ${ }^{75}$ tem-se revelado vantajosa no estabelecimento de uma relação saudável entre a sociedade e os cursos de água uma vez que pode contribuir para estabelecer estratégias efetivas de conservação, uso sustentável e gestão destes recursos.

\section{Referências bibliográficas}

${ }^{1}$ Abelho M. \& Graça M.A.S. 1996. Effects of eucalyptus afforestation on leaf litter dynamics and macroinvertebrate community structure of streams in Central Portugal. Hydrobiologia 324: 195-204

${ }^{2}$ Abelho M. \& Graça M.A.S. 1998. Litter in a temperate deciduous forest stream ecosystem. Hydrobiologia 386: 147-152

${ }^{3}$ Azevedo-Pereira H.V.S., Graça M.A.S. \& González J.M. 2006. Life history of Lepidostoma birtum in an Iberian stream and its role on organic matter processing. Hydrobiologia 559: 183-192

${ }^{4}$ Ferreira V., Castela J., Rosa P., Tonin A.M., Boyero L. \& Graça M.A.S. 2016a. Aquatic hyphomycetes, benthic macroinvertebrates and leaf litter decomposition in streams naturally differing in riparian vegetation. Aquat. Ecol. 50: 711-725

${ }^{5}$ Canhoto C. \& Graça M.A.S. 1998. Leaf retention: a comparative study between stream categories and leaf types. Verh. Internat. Verein. Limnol. 26: 990-993

${ }^{6}$ González J.M. \& Graça M.A.S. 2003. Conversion of leaf litter to secondary production by the shredder cadisfly Sericostoma vittatum. Freshwat. Biol. 48: 1578-1592

${ }^{7}$ Ferreira V., Encalada A.C. \& Graça M.A.S. 2012. Effects of litter diversity on decomposition and biological colonization of submerged litter in temperate and tropical streams. Freshwat. Sci. 31: 945-962

${ }^{8}$ Cortes R.M.V., Graça M.A.S. \& Monzón A. 1992. Replacement of alder by eucalyptus along two streams with different characteristics: differences on decay rates and 
consequences to the stream functioning. Verh. Internat. Verein. Limnol. 25: $1697-1702$

${ }^{9}$ Canhoto C. \& Graça M.A.S. 1996. Decomposition of Eucalyptus globulus leaves and 3 native leaf species (Alnus glutinosa, Castanea sativa and Quercus faginea) in a Portuguese low order stream. Hydrobiologia 333: 79-85

${ }^{10}$ Ferreira V., Chauvet E. \& Canhoto C. 2015a. Effects of experimental warming, litter species, and presence of macroinvertebrates on litter decomposition and associated decomposers in a temperate mountain stream. Can. J. Fish. Aquat. Sci. 72: 206-216

${ }^{11}$ Ferreira V., Elosegi A., Gulis V., Pozo J. \& Graça M.A.S. 2006a. Eucalyptus plantations affect fungal communities associated with leaf litter decomposition in Iberian streams. Arch. Hydrobiol. 166: 467-490

${ }^{12}$ Gonçalves A.L., Gama M., Ferreira V., Graça M.A.S. \& Canhoto C. 2007. The breakdown of Blue gum (Eucalyptus globulus Labill.) bark in a Portuguese stream. Fund. Appl. Limnol./Arch. Hydrobiol. 168: 307-315

13Pascoal C. \& Cássio F. 2004. Contribution of fungi and bacteria to leaf litter decomposition in a polluted river. Appl. Environ. Microbiol. 70: 5266-5273

${ }^{14}$ Ferreira V. \& Canhoto C. 2014. Effect of experimental and seasonal warming on litter decomposition in a temperate stream. Aquat. Sci. 76: 155-163

${ }^{15}$ Ferreira V., Raposeiro P.M., Pereira A., Cruz A.M., Costa A.C., Graça M.A.S. \& Gonçalves V. 2016b. Leaf litter decomposition in remote oceanic islands streams is driven by microbes and depends on litter quality and environmental conditions. Freshwat. Biol. 61: 783-799

${ }^{16}$ Pascoal C., Cássio F., Marcotegui A., Sanz B. \& Gomes P. 2005. The role of fungi, bacteria, and invertebrates in leaf litter breakdown in a polluted river. J. N. Am. Benthol. Soc. 24: 784-797

${ }^{17}$ Gulis V., Ferreira V. \& Graça M.A.S. 2006. Stimulation of leaf litter decomposition and associated fungi and invertebrates by moderate eutrophication: implications for stream assessment. Freshwat. Biol. 51: 1655-1669

${ }^{18}$ Graça M.A.S., Cressa C., Gessner M.O., Feio M.J., Callies K.A. \& Barrios C. 2001. Food quality, feeding preferences, survival and growth of shredders from temperate and tropical streams. Freshwat. Biol. 46: 947-957

${ }^{19}$ Graça M.A.S. \& Cressa C. 2010. Leaf quality of some tropical and temperate tree species as food resource for stream shredders. Internat. Rev. Hydrobiol. 95: 27-41

${ }^{20}$ Ferreira V., Graça M.A.S., de Lima J.L.M.P. \& Gomes R. 2006b. Role of physical fragmentation and invertebrate activity in the breakdown rate of leaves. Arch. Hydrobiol. 165: 493-513

${ }^{21}$ Duarte S, Cássio F., Ferreira V., Canhoto C. \& Pascoal C. 2016. Seasonal variability may affect microbial decomposers and leaf decomposition more than warming in streams. Microb. Ecol. 72: 263-276

${ }^{22}$ Ferreira V., Gulis V. \& Graça M.A.S. 2006c. Whole-stream nitrate addition affects litter decomposition and associated fungi but not invertebrates. Oecologia 149: 718-729

${ }^{23}$ Castela J., Ferreira V. \& Graça M.A.S. 2008. Evaluation of stream ecological integrity using litter decomposition and benthic invertebrates. Environ. Poll. 153: 440-449 
${ }^{24}$ Gama M., Gonçalves A.L., Ferreira V., Graça M.A.S. \& Canhoto C. 2007. Decomposition of fire exposed Eucalyptus leaves in a Portuguese lowland stream. Int. Rev. Hydrobiol. 92: 229-241

${ }^{25}$ Cornut J., Elger A., Lambrigot D., Marmonier P. \& Chauvet E. 2010. Early stages of leaf decomposition are mediated by aquatic fungi in the hyporheic zone of woodland streams. Freshwat. Biol. 55: 2541-2556

${ }^{26}$ Ferreira V. \& Chauvet E. 2011. Synergistic effects of water temperature and dissolved nutrients on litter decomposition and associated fungi. Global Change Biol. 17: $551-564$

${ }^{27}$ Duarte S., Pascoal C., Garabetian F., Cássio F. \& Charcosset J.-Y. 2009. Microbial decomposer communities are mainly structured by the trophic status in circumneutral and alkaline streams. Appl. Environ. Microbiol. 75: 6211-6221

${ }^{28}$ Ferreira V. \& Canhoto C. 2015. Future increase in temperature might stimulate litter decomposition in temperate cold water streams - evidence from a stream manipulation experiment. Freshwat. Biol. 60: 881-892

${ }^{29}$ Canhoto C. \& Graça M.A.S. 1999. Leaf barriers to fungal colonization and shredders (Tipula lateralis) consumption of decomposing Eucalyptus globulus. Microb. Ecol. 37: 163-172

${ }^{30}$ Graça M.A.S., Pozo J., Canhoto C. \& Elosegi A. 2002. Effects of Eucalyptus plantations on detritus, decomposers and detritivores in streams. TheScientificWorld J. 2: 1173-1185

${ }^{31}$ Ferreira V., Larrañaga A., Gulis V., Elosegi A., Basaguren A., Graça M.A.S. \& Pozo J. 2015b. The effect of eucalypt plantations on plant litter decomposition and macroinvertebrate communities in Iberian streams. For. Ecol. Manage. 335: 129-138

${ }^{32}$ Woodward G., Gessner M.O., Giller P.S., Gulis V., Hladyz S., Lecerf A., Malmqvist B., McKie B.G., Tiegs S.D., Cariss H., Dobson M., Elosegi A., Ferreira V., Graça M.A.S., Fleituch T., Lacoursiere J., Nistorescu M., Pozo J., Risnoveanu G., Schindler M., Vadineanu A., Vought L.B.-M. \& Chauvet E. 2012. Continental-scale effects of nutrient pollution on stream ecosystem functioning. Science 336: 1438-1440

${ }^{33}$ IPCC 2013. Summary for policymakers. In: Stocker T.F., Qin D., Plattner G.-K., Tignor M., Allen S.K., Boschung J., Nauels A., Xia Y., Bex V. \& Midgley P.M. (eds.) Climate Change 2013: The physical science basis. Contribution of Working Group I to the fifth assessment report of the Intergovernmental Panel on Climate Change, Cambridge University Press. U.K., Cambridge and U.S.A., New York, pp. 3-29

${ }^{34}$ Ferreira V. \& Voronina E. 2016. Impact of climate change on aquatic hypho- and terrestrial macromycetes. In: Marxsen J. (ed.) Climate change and microbial ecology: current research and future trends. Caister Academic Press. UK, Norfolk, pp. 53-72

${ }^{35}$ Canhoto C., Lima J.L.M.P. \& de Almeida A.T. 2013. Warming up a stream reach: design of a hydraulic and heating system. Limnol. Oceanogr. Methods 11: 410-417

${ }^{36}$ Miranda P., Coelho F.E.S., Tomé A.R. \& Valente M.A. 2002. 20th century Portuguese climate and climate scenarios. Climate change in Portugal. Scenarios, impacts and adaptation measures. In: Santos F.D., Forbes K. \& Moita R. (eds.) SIAM project. Gradiva Publications, Lda. Portugal, Lisboa, pp. 23-83 
${ }^{37}$ Morrill J.C., Bales R.C. \& Conklin M.H. 2005. Estimating stream temperature from air temperature: implications for future water quality. J. Environ. Eng. 131: 131-139

${ }^{38}$ Ylla I., Canhoto C. \& Romaní A. 2014. Effects of warming on stream biofilm organic matter use capabilities. Microb. Ecol. 68: 132-145

${ }^{39}$ Delgado C., Almeida S.F.P., Elias C.L., Ferreira V. \& Canhoto C. 2017. Response of biofilm growth to experimental warming in a temperate stream. Ecohydrology 10:e1868

${ }^{40}$ Mas-Martí E., Muñoz I., Oliva F. \& Canhoto C. 2015. Effects of increased water temperature on leaf litter quality and detritivore performance: a whole-reach manipulative experiment. Freshwat. Biol. 60: 184-197

${ }^{41}$ Jonsson M. \& Canhoto C. 2017. Climate change and freshwater invertebrates: their role in reciprocal freshwater-terrestrial resource fluxes. In: Johnson S.N. \& Jones T.H. (eds.) Global climate change and terrestrial invertebrates. John Wiley \& Sons, Ltd. UK, Chichester, pp. 274-294

${ }^{42}$ Lei da Água 58/2005. 2005. Diário da República (Série I-A) 249: 7280-7310

${ }^{43}$ Gessner M.O. \& Chauvet E. 2002. A case for using litter breakdown to assess functional stream integrity. Ecol. Appl. 12: 498-510

${ }^{44}$ Ferreira V., Koricheva J., Pozo J. \& Graça M.A.S. 2016c. A meta-analysis on the effects of changes in the composition of native forests on litter decomposition in streams. For. Ecol. Manage. 364: 27-38

${ }^{45}$ Feio M.J., Alves T., Boavida M., Medeiros A. \& Graça M.A.S. 2010. Functional indicators of stream health: a river-basin approach. Freshwat. Biol. 55: 1050-1065

${ }^{46}$ Allan J. D. \& Castillo M M. 2007. Stream ecology: structure and function of running waters. Springer. Netherlands

${ }^{47}$ Hauer F.R. \& Lamberti G.A. 2017. Methods in stream ecology, Vol. 2: Ecosystem function. $3^{\text {rd }}$ edition. Academic Press. U.K., London

${ }^{48}$ Sroczynska K., Claro M., Range P., Wasiak K., Wojtal-Frankiewicz A., Ben-Hamadou R., Leitão F. \& Chícharo L. 2016. Habitat-specific benthic metabolism in a Mediterranean-type intermittent stream. Ann. Limnol. - Int. J. Limnol. 52: 243-252

${ }^{49}$ Dunck B., Lima-Fernandes E., Cássio F., Cunha A., Rodrigues L. \& Pascoal C. 2015. Responses of primary production, leaf litter decomposition and associated communities to stream eutrophication. Environ. Poll. 202: 32-40

${ }^{50}$ Rakowski C. \& Cardinale B.J. 2016. Herbivores control effects of algal species richness on community biomass and stability in a laboratory microcosm experiment. Oikos 125: 1627-1635

${ }^{51}$ Niyogi D.K., Lewis Jr W.M. \& McKnight D.M. 2002. Effects of stress from mine drainage on diversity, biomass, and function of primary producers in mountain streams. Ecosystems 5: 554-567

${ }^{52}$ Townsend S., Schult J., Douglas M. \& Lautenschlager A. 2017. Recovery of benthic primary producers from flood disturbance and its implications for an altered flow regime in a tropical savannah river (Australia). Aq. Bot. 136: 9-20

53 Pereira A., Geraldes P., Lima-Fernandes E., Fernandes I., Cássio F. \& Pascoal C. 2016. Structural and functional measures of leaf-associated invertebrates and fungi as predictors of stream eutrophication. Ecol. Ind. 69: 648-656 
${ }^{54}$ Delgado C., Almeida S.F.P., Elias C.L., Ferreira V. \& Canhoto C. 2017. Response of biofilm growth to experimental warming in a temperate stream. Ecohydrology 10: e1868

${ }^{55}$ Rosa J., Ferreira V., Canhoto C. \& Graça M.A.S. 2013. Combined effects of water temperature and nutrients concentration on periphyton respiration - implications of global change. Int. Rev. Hydrobiol. 98: 14-23

${ }^{56}$ Gessner M.O. \& Newell S.Y. 2002. Biomass, growth rate, and production of filamentous fungi in plant litter. In: Hurst C.J., Knudsen G.R., McInerney M.J., Stetzenbach L.D. \& Walter M.V. (eds.) Manual of Environmental Microbiology. 2nd edn. ASM Press. U.S.A., Washington, D.C., pp. 1-19

${ }^{57}$ Anastácio P.M. \& Marques J.C. 1995. Population biology and production of the red swamp crayfish Procambarus clarkii (Girard) in the lower Mondego river valley, Portugal. J. Crust. Biol. 15: 156-168

${ }^{58}$ Cabral J.A. \& Marques J.C. 1999. Life history, population dynamics and production of eastern mosquitofish, Gambusia holbrooki (Pisces, Poeciliidae), in rice fields of the lower Mondego River Valley, western Portugal. Acta Oecologia - Int. J. Ecol. 20: 607-620

${ }^{59}$ MEA 2005. Millennium ecosystem assessment: ecosystems and human well-being: the assessment series. Island Press. U.S.A., Washington, DC

${ }^{60}$ Acuña V., Díez J. R., Flores L., Meleason M. \& Elosegi A. 2013. Does it make economic sense to restore rivers for their ecosystem services? J. Appl. Ecol. 50: 988-997

${ }^{61}$ Harrison P.A., Vandewalle M., Sykes M.T., Berry P.M., Bugter R., de Bello F., Feld C.K., Grandin U., Harrington R., Haslett J. R., Jongman R.H.G., Luck W., Martins da Silva P., Moora M., Settele J., Sousa J.P. \& Zobel M. 2010. Identifying and prioritising services in European terrestrial and freshwater ecosystems. Biodiv. Conserv. 19: 2791-2821

${ }^{62}$ Palmer M.A. \& Richardson D.C. 2009. Provisioning services: a focus on fresh water. In: Levin S.A., Carpenter S.R., Godfray H.C.J., Kinzing A.P., Loreau M., Losos J.B., Walker B. \& Wilcove D.S. (eds.) The Princeton guide to ecology. Princeton University Press. U.K., Princeton, pp. 625-633

${ }^{63}$ Brauman K.A., Daily G.C., Duarte T.K. \& Mooney H.A. 2007. The nature and value of ecosystem services: An overview highlighting hydrologic services. Annu. Rev. Environ. Resour. 32: 67-98

${ }^{64}$ Sabater S. 2008. Alterations of the global water cycle and their effects on river structure, function and services. Freshwat. Rev. 1: 75-88

${ }^{65}$ Thorp J.H., Flotemersch J.E., Delong M.D., Casper A.F., Thoms M.C., Ballantyne F., Williams B.S., O'Neil B.J. \& Haase C.S. 2010. Linking ecosystem services, rehabilitation, and river hydrogeomorphology. BioScience 60: 67-74

${ }^{66}$ Jabiol J., Bruder A., Gessner M.O., Makkonen M., McKie B.G., Peeters E.T.H.M., Vos V.C.A., Chauvet E. 2013. Diversity patterns of leaf-associated aquatic hyphomycetes along a broad latitudinal gradient. Fungal Ecol. 6: 439-448

${ }^{67}$ Jonsson M. \& Malmqvist B. 2000. Ecosystem process rate increases with animal species richness: evidence from leaf-eating, aquatic insects. Oikos 89: 519-523

${ }^{68}$ Mace G.M., Norris K. \& Fitter A.H. 2012. Biodiversity and ecosystem services: a multilayered relationship. Trends Ecol. Evol. 27: 19-26 
${ }^{69}$ Hoeinghaus D.J., Agostinho A.A., Gomes L.C., Pelicice F.M., Okada E.K., Latini J.D., Kashiwaqui E. A.L. \& Winemiller K.O. 2009. Effects of river impoundment on ecosystem services of large tropical rivers: embodied energy and market value of artisanal fisheries. Conserv. Biol. 23: 1222-1231

${ }^{70}$ Mooney H., Larigauderie A., Cesario M., Elmquist T., Hoegh-Guldberg O., Lavorel S., Mace G.M., Palmer M., Scholes R. \& Yahara T. 2009. Biodiversity, climate change, and ecosystem services. Curr. Opin. Environ. Sustain. 1: 46-54

${ }^{71}$ Boyero L., Pearson R.G., Gessner M.O., Barmuta L.A., Ferreira V., Graça M.A.S., Dudgeon D., Boulton A.J., Callisto M., Chauvet E., Helson J.E., Bruder A., Albariño R.J., Yule C.M., Arunachalam M., Davies J.N., Figueroa R., Flecker A. S., Ramírez A., Death R. G., Iwata T., Mathooko J. M., Mathuriau C., Gonçalves J. F. Jr., Moretti M.S., Jinggut T., Lamothe S., M'Erimba C., Ratnarajah L., Schindler M.H., Castela J., Buria L.M., Cornejo A., Villanueva V.D. \& West D.C. 2011. A global experiment suggests climate warming will not accelerate litter decomposition in streams but might reduce carbon sequestration. Ecol. Lett. 14: 289-294

${ }^{72}$ Pejchar L. \& Mooney H.A. 2009. Invasive species, ecosystem services and human well-being. Trends Ecol. Evol. 24: 497-504

${ }^{73}$ Anton C., Young J., Harrison P.A., Musche M., Bela G., Feld C.K., Harrington R., Haslett J.R., Pataki G., Rounsevell M.D.A., Skourtos M., Sousa J.P., Sykes M.T., Tinch R., Vandewalle M., Watt A. \& Settele J. 2010. Research needs for incorporating the ecosystem service approach into EU biodiversity conservation policy. Biodiv. Conserv. 19: 2979-2994

${ }^{74}$ Balmford A. \& Bond W. 2005. Trends in the state of nature and their implications for human well-being. Ecol. Lett. 8: 1218-1234

${ }^{75}$ Fisher B., Turner K.R. \& Morling P. 2009. Defining and classifying ecosystem services for decision making. Ecol. Econ. 68: 643-653 